Check for updates

Cite this: Phys. Chem. Chem. Phys., 2018, 20, 7457

Received 9th January 2018, Accepted 8th February 2018

DOI: $10.1039 / c 8 c p 00171 e$

rsc.li/pccp

\title{
XUV photodesorption of carbon cluster ions and ionic photofragments from a mixed methane-water ice
}

\author{
T. Suhasaria, (D)*a J. D. Thrower, (D) ${ }^{a}$ R. Frigge, $\dagger^{a b}$ S. Roling, ${ }^{a}$ M. Bertin, ${ }^{c}$ X. Michaut, ${ }^{c}$ \\ J.-H. Fillion ${ }^{\mathrm{c}}$ and H. Zacharias ${ }^{\text {ad }}$
}

\begin{abstract}
The photochemical processing of $\mathrm{CH}_{4}: \mathrm{D}_{2} \mathrm{O}$ 1:3.3 ice mixture adsorbed on an HOPG surface in the XUV regime was investigated using pulses obtained from the Free-electron LASer in Hamburg (FLASH) facility. Ice films were exposed to femtosecond pulses with a photon energy of $h \nu=40.8 \mathrm{eV}$, consistent with the Hell resonance line. Cationic species desorbing directly from the ice films were detected using time-of-flight (ToF) mass spectrometry. Simple ions formed through the fragmentation of the parent molecules and subsequent recombination reactions were detected and are consistent with efficient $\mathrm{D}^{+}$ and $\mathrm{H}^{+}$ejection from the parent species, similar to the case for low energy electron irradiation. The FEL fluence dependencies of these ions are linear or exhibit a non-linear order of up to 3. In addition, a series of $\mathrm{C}_{n}{ }^{+}$cluster ions (with $n$ up to 12) were also identified. These ions display a highly non-linear desorption yield with respect to the FEL fluence, having an order of 6-10, suggesting a complex multistep process involving the primary products of $\mathrm{CH}_{4}$ fragmentation. Two-pulse correlation measurements were performed to gain further insight into the underlying reaction dynamics of the photo-chemical reactions. The yield of the $\mathrm{D}_{2} \mathrm{O}$ derived products displayed a different temporal behaviour with respect to the $\mathrm{C}_{n}{ }^{+}$ions, indicating the presence of very different reaction pathways to the two families of ionic products.
\end{abstract}

\section{Introduction}

Solid state photochemical processing of mixed molecular ices provides an important energetic route toward the formation of complex species in the interstellar medium (ISM). ${ }^{1}$ The presence of such ices in dense interstellar clouds has been confirmed through observations in the infrared region. Consisting primarily of water $\left(\mathrm{H}_{2} \mathrm{O}\right)^{2}$ ice along with other species such as carbon monoxide $(\mathrm{CO})$, carbon dioxide $\left(\mathrm{CO}_{2}\right)$, methane $\left(\mathrm{CH}_{4}\right)$, methanol $\left(\mathrm{CH}_{3} \mathrm{OH}\right)$ and ammonia $\left(\mathrm{NH}_{3}\right){ }^{3}$ they form icy mantles on sub-micron scale grains of carbonaceous or silicate mineral character ${ }^{4}$ through a combination of simple freeze-out from the gas phase (e.g. CO) and

\footnotetext{
${ }^{a}$ Physikalisches Institut, Westfälische Wilhelms Universität, Wilhelm Klemm Straße 10, 48149 Münster, Germany. E-mail: john.thrower@uni-muenster.de, h.zacharias@uni-muenster.de

${ }^{b}$ Center for Nanotechnology (CeNTech), Westfälische Wilhelms-Universität, 48149 Münster, Germany

${ }^{c}$ Sorbonne Université, Observatoire de Paris, PSL Research University, Laboratoire d'Etudes du Rayonnement et de la Matière en Astrophysique et Atmosphères, CNRS UMR 8112, 75005 Paris, France

${ }^{d}$ Center for Soft Nanoscience, Westfälische Wilhelms Universität, 48149, Münster, Germany

$\dagger$ Present address: Department of Chemistry, University of Hawaii at Manoa, Honolulu, Hawaii, HI, 96822, USA.
}

reactive accretion with, for example, hydrogen addition leading to species such as $\mathrm{H}_{2} \mathrm{O}$ and $\mathrm{CH}_{3} \mathrm{OH} .{ }^{5}$ In addition, deuterated species such as heavy water $\left(\mathrm{D}_{2} \mathrm{O}\right)$ have been observed. ${ }^{6}$ Non-thermal processes, driven by the interaction of photons and charged particles, within these ices are thought to provide both a means to form more complex species, through the formation of reactive intermediates in the ice, and to promote desorption from ices in low temperature environments where thermal desorption is inefficient. In the diffuse medium, as well as at the edges of molecular clouds, grains are exposed to the interstellar radiation field (ISRF) ${ }^{7}$ while, at higher extinction, cosmic rays and the VUV photons generated as a result of their interaction with $\mathrm{H}_{2}$ provide the dominant energy sources. ${ }^{8} \mathrm{XUV}$ radiation is also emitted by young stars in the form of discrete atomic line transitions ${ }^{9,10}$ which are of importance in circumstellar regions. ${ }^{11}$ The intensity of XUV radiation is at least two to three orders of magnitude lower than the VUV radiation ${ }^{12}$ but with a higher penetration depth in the circumstellar disk. The highly energetic XUV radiation interacts strongly with ice components and acts as ionizing radiation to initiate ion-molecule reactions within the ice and at the same time desorb the ionized products from the surface. Until relatively recently, the systematic investigation of energetic processing at such wavelengths in the laboratory was 
difficult, but the advent of free-electron lasers in the XUV, for example the Free-electron LASer in Hamburg (FLASH), has provided a powerful tool for extending our understanding of photon driven processes to this more energetic regime. For example, Siemer et al. ${ }^{13}$ demonstrated the relevance of chemical reactions in $\mathrm{D}_{2} \mathrm{O}$ ice by exposure to XUV radiation at photon energies of $38.15 \mathrm{eV}$ and $57.1 \mathrm{eV}$. The desorption of a variety of cluster ions such as $\left(\mathrm{D}_{2} \mathrm{O}\right)_{n}{ }^{+}$ and $\left(\mathrm{D}_{2} \mathrm{O}\right)_{n} \mathrm{D}^{+}$was observed, along with fragments and simple ionic products including $\mathrm{D}_{2} \mathrm{O}^{+}, \mathrm{OD}^{+}, \mathrm{O}^{+}$and $\mathrm{D}^{+}$. At these higher energies, several times the typical values of ionization potentials, it is clear that ionization plays a key role in driving these chemical and desorption processes. It is natural to consider the effect of the interaction of XUV photons with more complex ice mixtures containing, for example, carbon sources such as $\mathrm{CH}_{4}$.

$\mathrm{CH}_{4}$ ice has been observed in a variety of sources in the ISM as discussed by Boogert et al. ${ }^{2}$ who compared the $\mathrm{CH}_{4}$ ice abundance relative to $\mathrm{H}_{2} \mathrm{O}$ for various sources. This study suggested an upper limit of $<3 \%$ for quiescent dark cloud regions, and abundances between $0.4-1.6 \%$ for comets, $1-11 \%$ for low-mass young stellar objects (LYSOs) and values of 1-3\% in massive young stellar objects (MYSOs). $\mathrm{CH}_{4}$ is believed to be formed through surface reactions on low temperature $(\sim 15 \mathrm{~K})$ grains and is thought to be typically embedded in a polar matrix such as $\mathrm{H}_{2} \mathrm{O} .{ }^{14}$ Aside from the dominant carbon containing ice species, CO, which is implicated in the formation of $\mathrm{CH}_{3} \mathrm{OH}, \mathrm{CH}_{4}$ is considered a starting point for the formation of complex organic molecules. Various laboratory experiments have been carried out to probe the non-thermal processing of pure $\mathrm{CH}_{4}{ }^{15-21}$ and $\mathrm{H}_{2} \mathrm{O}: \mathrm{CH}_{4}$ mixed ice. ${ }^{16,22-24}$ In both pure and mixed $\mathrm{CH}_{4}$ ices, the primary products were found to be simple hydrocarbons. Kaiser and Roessler ${ }^{15}$ demonstrated the formation of long chain alkanes, $\mathrm{C}_{x} \mathrm{H}_{x+2}$ with up to $x=14$, through the exposure of pure $\mathrm{CH}_{4}$ ice to $9 \mathrm{MeV} \propto$ particles and $7.3 \mathrm{MeV}$ protons. In the presence of $\mathrm{H}_{2} \mathrm{O}$, products such as $\mathrm{CH}_{3} \mathrm{OH}$, formaldehyde $\left(\mathrm{H}_{2} \mathrm{CO}\right), \mathrm{CO}, \mathrm{CO}_{2}$ are also typically generated, while Moore and Hudson ${ }^{22}$ and Öberg et al. ${ }^{24}$ additionally found acetaldehyde $\left(\mathrm{CH}_{3} \mathrm{CHO}\right)$ and ethanol $\left(\mathrm{C}_{2} \mathrm{H}_{5} \mathrm{OH}\right)$.

Here we have extended our previous investigations of XUV processing of $\mathrm{D}_{2} \mathrm{O}$ ice to a mixed $\mathrm{CH}_{4}: \mathrm{D}_{2} \mathrm{O}$ ice, subsequently exposed to XUV photons at the HeII resonance line wavelength of $\lambda=30.4 \mathrm{~nm}(h \nu=40.8 \mathrm{eV})$. Ionic photochemical products directly desorbed from the ice film were detected through time-of-flight (ToF) mass spectrometry, revealing simple ionic species attributed to fragmentation of the individual ice components, reaction products and a strong series of ionic carbon clusters $\mathrm{C}_{n}{ }^{+}$with $n$ extending up to a value of at least 12 . We additionally performed measurements of the laser fluence dependence of the ion desorption yields, complemented by two-pulse correlation measurements to gain further insight into the reactions occurring.

\section{Experimental methods}

\subsection{Ice growth and irradiation}

The $\mathrm{CH}_{4}: \mathrm{D}_{2} \mathrm{O}$ ice mixture was grown under ultrahigh vacuum (UHV) conditions in a chamber described previously by Siemer et al. ${ }^{13}$ The UHV chamber had a base pressure of $5 \times 10^{-10} \mathrm{mbar}$ and was equipped with a flowing liquid helium cryostat (Cryovac Konti UHV). The ice films were grown on a highly oriented pyrolytic graphite (HOPG; Optigraph ZYA grade, mosaic spread $=0.4^{\circ}$ ) which was clamped to the end of the cryostat with silver paste ensuring good thermal contact between the sample and the cryostat. The sample was cooled to $15 \mathrm{~K}$ as monitored by a calibrated silicon diode, mounted close to the sample. The HOPG sample was prepared prior to mounting in the chamber by cleaving the top layers with adhesive tape and through subsequent annealing to $\mathrm{ca} .500 \mathrm{~K}$ under UHV prior to measurements. $\mathrm{CH}_{4}$ (99.995\%; Westfalen AG) and $\mathrm{D}_{2} \mathrm{O}(100 \%$ atoms of $\mathrm{D}$; abcr $\mathrm{GmbH})$ were used for the preparation of the ice mixture. $\mathrm{CH}_{4}$ was used directly without further purification whereas $\mathrm{D}_{2} \mathrm{O}$ was purified by several freezepump-thaw cycles. $\mathrm{D}_{2} \mathrm{O}$ was used to allow for the identification of photon-induced chemical products using mass spectrometry. The ice mixture was prepared in a high vacuum manifold and then introduced into the UHV chamber via a precision leak valve such that the ice film was grown through background deposition. The total exposure of the deposited ice mixture was measured in Langmuir $\left(1 \times 10^{-6}\right.$ Torr $\left.\mathrm{s}\right)$ as monitored using a quadrupole mass spectrometer (QMS; Hiden Analytical HAL 7) which was calibrated for the individual components by comparison to the pressure as determined using a hot-cathode UHV ionization gauge (Arun Microelectronics Ltd), corrected by the sensitivity factors $^{25}$ quoted by the manufacturer. An error of $10 \%$ was considered in the pressure determination by the ionization gauge. In this way, the composition of the gas dose was determined in situ. At a sample temperature of $15 \mathrm{~K}$ it is reasonable to assume a sticking coefficient of unity for both $\mathrm{CH}_{4}$ and $\mathrm{D}_{2} \mathrm{O}$ and we thus consider the gas phase composition to be a reasonable representation of that of the ice film grown.

Under this assumption, for each component the exposure, in $\mathrm{L}$, was converted to a surface coverage of $N_{\text {ads }}$ molecules $\mathrm{cm}^{-2}$ using the Hertz-Knudsen formula:

$$
N_{\mathrm{ads}}=\frac{p}{\sqrt{2 \pi m k_{\mathrm{B}} T}} \cdot t
$$

where, $p$ is the gas pressure in Torr, $m$ the molecular mass, $k_{\mathrm{B}}$ the Boltzmann constant, $T$ the gas temperature in Kelvin $(300 \mathrm{~K})$ and $t$ the dose time. The obtained values yield a molecular $\mathrm{CH}_{4}: \mathrm{D}_{2} \mathrm{O}$ ratio of $1: 3.3$. The surface coverage was converted into the number of adsorbed monolayers (MLs) by considering typical values for the density of each species in a monolayer. For $\mathrm{D}_{2} \mathrm{O}$ a value of $1.1 \times 10^{15}$ molecules $\mathrm{cm}^{-2}$ was assumed, according to the value obtained for $\mathrm{H}_{2} \mathrm{O}$ adsorbed on graphite $(0001) .{ }^{26}$ In the case of $\mathrm{CH}_{4}$ a value of $6.54 \times 10^{14}$ molecules $\mathrm{cm}^{-2}$ was obtained for $\mathrm{CH}_{4}$ by considering the low energy electron diffraction (LEED) pattern of $\mathrm{CH}_{4}$ adsorbed on graphite at low temperature. ${ }^{27} \mathrm{CH}_{4}$ shows a $\sqrt{3} \times \sqrt{3} R 30^{\circ}$ structure, allowing the molecular density of $\mathrm{CH}_{4}$ to be determined from the unit cell area. We note that these values are for equivalent saturated monolayers grown on the HOPG surface and do not take into account the effects of, for example, porous water ice growth which is known to occur at low temperature. ${ }^{28,29}$ The thickness of the deposited ice film in nm was therefore estimated by considering densities determined in 
Table 1 The coverage and the ice film thickness deposited on the HOPG

\begin{tabular}{|c|c|c|c|c|}
\hline Ice & Exposure L & $\begin{array}{l}\text { Coverage } \\
\text { molecules } \mathrm{cm}^{-2}\end{array}$ & Coverage ML & $\begin{array}{l}\text { Ice thickness } \\
\mathrm{nm}\end{array}$ \\
\hline $\mathrm{D}_{2} \mathrm{O}$ & $(27.4 \pm 2.7)$ & $\left(1.24 \pm 0.11 \times 10^{16}\right)$ & $(10.8 \pm 1.1)$ & $(6.3 \pm 0.6)$ \\
\hline $\mathrm{CH}_{4}$ & $(7.4 \pm 0.7)$ & $\left(3.74 \pm 0.37 \times 10^{15}\right)$ & $(5.7 \pm 0.6)$ & $(2.1 \pm 0.2)$ \\
\hline
\end{tabular}

previous studies at relevant temperatures. The density of $\mathrm{D}_{2} \mathrm{O}$ was taken to be $\rho=0.60 \mathrm{~g} \mathrm{~cm}^{-3}$ as determined for $\mathrm{H}_{2} \mathrm{O}$ ice by using the uptake of $\mathrm{CH}_{4}$ in the porous structure of the ice. ${ }^{30} \mathrm{In}$ addition a $\mathrm{CH}_{4}$ density of $\rho=0.47 \mathrm{~g} \mathrm{~cm}^{-3}$ was taken from the study of Satorre et $a l^{31}$ allowing us to estimate a total ice thickness of $(8.4 \pm 0.6 \mathrm{~nm})$. Table 1 lists the background gas exposure, coverage, and thickness of the ice film on the surface with respect to the two individual components.

XUV photon irradiation of the ice mixture was performed using pulsed radiation from the FLASH free electron laser. ${ }^{32}$ All irradiation experiments were performed with the sample at $15 \mathrm{~K}$. A photon energy of $h \nu=40.8 \mathrm{eV}(\lambda=30.4 \mathrm{~nm})$ corresponding to the HeII line was used. The FEL was operated in single bunch mode and at a repetition rate of $10 \mathrm{~Hz}$. An average energy per pulse of $(29.6 \pm 7) \mu \mathrm{J}$ and an average pulse duration of $c a .80 \mathrm{fs}$ were employed. $\hat{p}$-Polarized XUV photons were incident on the HOPG surface at an angle of $\theta=67.5^{\circ}$ to the surface normal. The beam was focussed by an ellipsoidal mirror with a focal length $f=2 \mathrm{~m}$. The spatial profile, and hence the spot size of the beam at the sample position were determined using an X-ray CCD camera positioned at an equivalent focus position, to which the beam was directed by a moveable quartz plate. As a result of the oblique incidence angle, the beam produced an ellipsoidal spot with an area of $(0.9 \pm 0.1) \times 10^{-3} \mathrm{~cm}^{2}$ yielding an average fluence of $(32.9 \pm 8) \mathrm{mJ} \mathrm{cm}^{-2}$ on the sample.

Ionic species desorbed directly during exposure of the ice film to the XUV radiation were selected according to their mass to charge ratio $(\mathrm{m} / \mathrm{z})$ using a Wiley-McLaren type linear time-offlight (ToF) mass spectrometer. The ion signal on the micro channel plate of the ToF was monitored using a digital oscilloscope, gated and forwarded to the computer for storage. The corresponding pulse energy for each laser shot was stored and the mass spectra were generated by averaging over, typically, 1000 shots.

The use of femtosecond duration pulses allows an examination of the underlying ultrafast dynamics of the photochemical reactions through time-resolved measurements. For this purpose, the split-and-delay unit (SDU) $)^{33-35}$ was employed to split the incident XUV pulses into two temporally separated components. The SDU produces two identical jitter-free pumpprobe pulses provided with a tuneable temporal separation of -2 to $+6 \mathrm{ps}$. Siemer et l. $^{13}$ previously performed similar measurements for elucidating the XUV photochemical reaction mechanisms in $\mathrm{D}_{2} \mathrm{O}$ ice. The spatial overlap of the two pulses, after recombination, was monitored using the X-ray $\mathrm{CCD}$ camera discussed above. The stability of the overlap was monitored over the entire delay range between the pump-probe beams. At the employed photon energy the SDU has a transmittance of $48 \%{ }^{35}$ which is taken into account when determining the incident fluence.

\subsection{Optical properties and the energy deposition in the system}

In order to understand the mechanism of desorption of photochemical products, the XUV absorption characteristics of the $\mathrm{CH}_{4}: \mathrm{D}_{2} \mathrm{O}$ ice film on HOPG need to be considered. The refraction, reflection and absorption of light by a material can be described in terms of the complex refractive index, $\mathbf{n}$ :

$$
\mathbf{n}=n-i k=(1-\delta)-i \beta
$$

where $n$ is the real part of the refractive index and $k$ is the absorption coefficient from which the extinction coefficient in the Beer-Lambert law can be determined. In the absence of direct measurements of $n$ and $k$ for the ice components used, the optical constants for $\mathrm{CH}_{4}, \mathrm{D}_{2} \mathrm{O}$ and HOPG were derived by considering the relevant atomic scattering factors, as obtained from the CXRO database. $\neq^{36}$ The database provides, given the material density and photon energy, the complex refractive index in terms of the two parameters, $\delta$ and $\beta$, in eqn (2). From the optical constants for the individual ice components, values of $n=0.95$ and $k=0.04$ were obtained for the $\mathrm{CH}_{4}: \mathrm{D}_{2} \mathrm{O}$ ice mixture by applying the Maxwell-Garnett mixing rule. ${ }^{37}$ By considering the two interfaces (vacuum-ice and ice-HOPG) the fraction of the incident light transmitted through and absorbed by the ice film and the HOPG substrate was determined using the Fresnel equations, taking into account the refraction at each interface. The vacuum-ice mixture interface was found to reflect $5.5 \%$ of the incident light while $40 \%$ of that transmitted was absorbed by the ice film. Of the remaining light that reached the ice-HOPG substrate, $60 \%$ was reflected resulting in total absorbed fluences of $c a .16 .4 \mathrm{~mJ} \mathrm{~cm}^{-2}$ and $7.7 \mathrm{~mJ} \mathrm{~cm}^{-2}$ for the ice mixture and the HOPG substrate, respectively.

Given that some of the incident beam is absorbed by the HOPG substrate, the extent to which the desorption of carbon cluster ions from the bare HOPG surface occurs needs to be considered. Fig. 1 shows the ion desorption spectrum obtained for XUV irradiation of the bare HOPG surface for two different incident fluences. Clearly, at an incident fluence of $(78 \pm 11) \mathrm{mJ} \mathrm{cm}^{-2}, \mathrm{C}_{n}^{+}$clusters (up to $n=11$ ) are ejected from the bare HOPG surface. However, as shown in the inset, the yield of $\mathrm{C}_{n}^{+}$clusters is significantly reduced at an incident fluence of $c a .(40 \pm 10) \mathrm{mJ} \mathrm{cm}^{-2}$. It should be noted that in this case the SDU was not inserted into the beamline and significantly higher incident fluences were attainable at the sample. Thus, considering the lower incident fluence employed in the measurements performed with the adsorbed film and the reduced intensity reaching the ice-HOPG interface as a result of absorption by the ice film, we do not expect a significant cluster yield originating from the substrate.

\section{Results}

\subsection{Time-of-flight mass spectra of XUV desorbed ionic species}

Fig. 2 shows the ToF mass spectra of ions directly desorbed from the $\mathrm{CH}_{4}: \mathrm{D}_{2} \mathrm{O}(1: 3.3)$ ice mixture during irradiation with $40.8 \mathrm{eV}$ photons. This spectrum is the average of that obtained over 1000 individual laser shots with a typical incident fluence

† For additional information see: http://henke.lbl.gov/optical_constants/ 


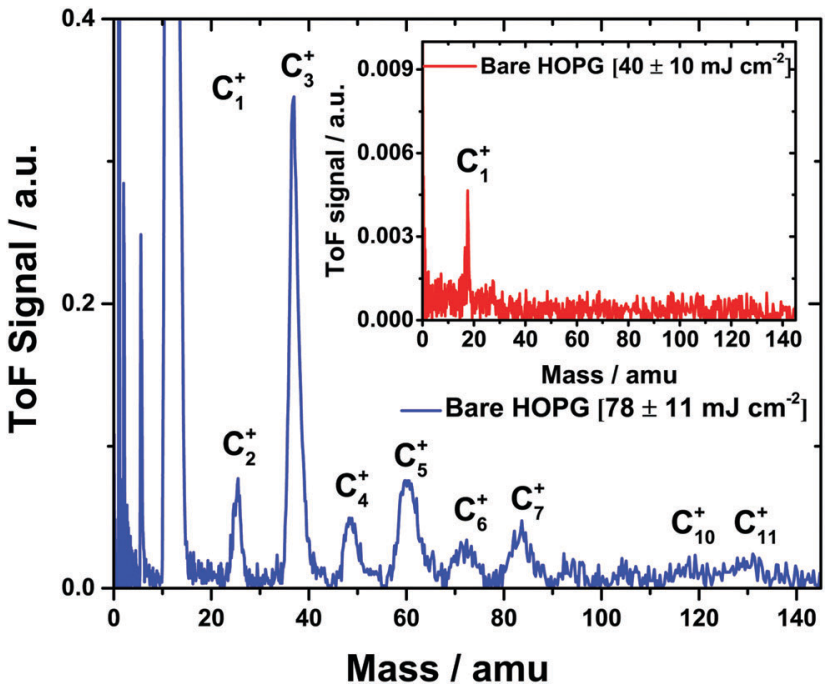

Fig. 1 ToF mass spectrum of photo-desorbed ions from the bare HOPG surface kept at $15 \mathrm{~K}$ during exposure to $h \nu=40.8 \mathrm{eV}$ photons at an incident fluence of $(78 \pm 11) \mathrm{mJ} \mathrm{cm}^{-2}$. The inset shows a spectrum acquired under identical conditions but for an incident fluence of $(40 \pm 10) \mathrm{mJ} \mathrm{cm}^{-2}$.

of $(35 \pm 6) \mathrm{mJ} \mathrm{cm}{ }^{-2}$. We distinguish between two families of ionic desorption products corresponding to simple ionic species and carbon cluster ions, and label the masses in black and red, respectively. Desorption signals at 1 and 2 amu can be attributed to the desorption of $\mathrm{H}^{+}$and $\mathrm{D}^{+}$, respectively, consistent with proton desorption from the two individual ice components. We cannot exclude some contribution to the $2 \mathrm{amu}$ signal from $\mathrm{H}_{2}{ }^{+} .4 \mathrm{amu}$ is a signature of $\mathrm{D}_{2}{ }^{+}$, while the signal at $3 \mathrm{amu}$ can be explained by $\mathrm{HD}^{+}$desorption, which indicates a photochemical pathway involving both of the ice components. In addition, signals at 16, 18 and $20 \mathrm{amu}$ can be attributed to the expected fragment ions from $\mathrm{D}_{2} \mathrm{O}$, namely, $\mathrm{O}^{+}, \mathrm{OD}^{+}$and $\mathrm{D}_{2} \mathrm{O}^{+}$, respectively. Similarly, those at 14,15 and 16 amu correspond to $\mathrm{CH}_{2}{ }^{+}, \mathrm{CH}_{3}{ }^{+}$ and $\mathrm{CH}_{4}{ }^{+}$, respectively. As with $3 \mathrm{amu}$, the observed desorption of ions with masses of 17 and 19 amu can be ascribed to photochemical desorption products involving primary photoproducts from the two individual ice components, $\mathrm{OH}^{+}$and $\mathrm{HDO}^{+}$, respectively. In our previous investigation involving pure $\mathrm{D}_{2} \mathrm{O}$ ice, ${ }^{13}$ the formation of $\mathrm{D}_{2} \mathrm{O}$ clusters $\left(\mathrm{D}_{2} \mathrm{O}\right)_{n}{ }^{+}$and $\left(\mathrm{D}_{2} \mathrm{O}\right)_{n} \mathrm{D}^{+}$was highlighted. We observe a peak at $40 \mathrm{amu}$ which could, in principle, be assigned to $\left(\mathrm{D}_{2} \mathrm{O}\right)_{2}{ }^{+}$although the lack of any signature of the more stable $\left(\mathrm{D}_{2} \mathrm{O}\right)_{n} \mathrm{D}^{+}$would appear to rule this out. Siemer et al. ${ }^{13}$ also observed the desorption of $\mathrm{D}_{2} \mathrm{O}_{2}$ at a mass of 36 $\mathrm{amu}$. In the present case we cannot rule out the presence of this ion, although a secure identification is precluded by the presence of the broad ion peak centred at $36.7 \mathrm{amu}$ which, as discussed later, is attributed to $\mathrm{C}_{3}{ }^{+}$.

In addition to these simple species, we observe a series of peaks centered around 28 amu which could be attributed to the $\mathrm{C}_{2}$ hydrocarbon species $\mathrm{C}_{2} \mathrm{H}_{3}{ }^{+}, \mathrm{C}_{2} \mathrm{H}_{4}{ }^{+}, \mathrm{C}_{2} \mathrm{H}_{5}{ }^{+}$, and $\mathrm{C}_{2} \mathrm{H}_{6}{ }^{+}$with

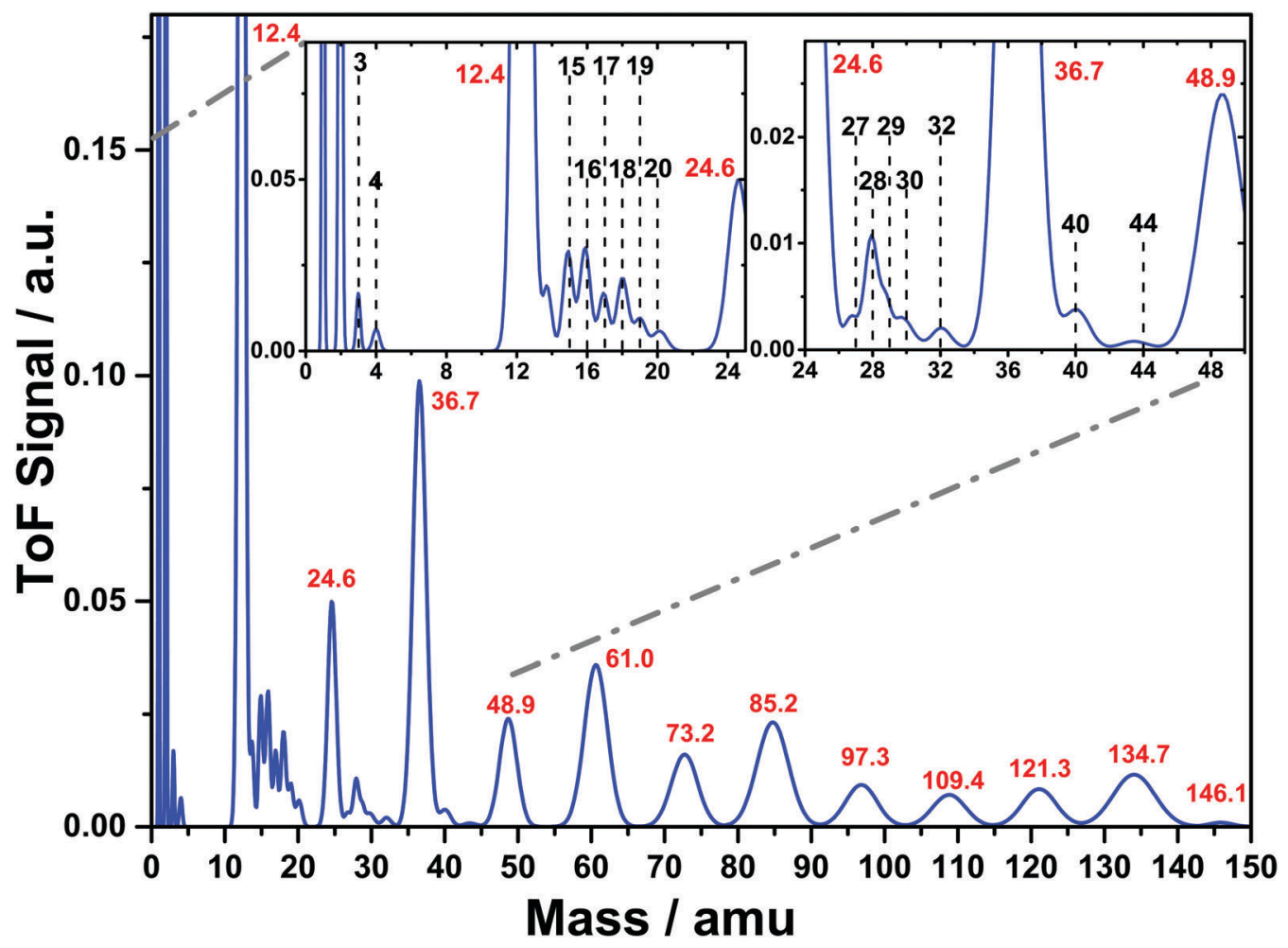

Fig. 2 ToF mass spectra of the photo-desorbed ions after irradiation of the $\mathrm{CH}_{4}: \mathrm{D}_{2} \mathrm{O} 1: 3.3$ ice mixture on the HOPG surface kept at $15 \mathrm{~K}$ with an energy per pulse of $(31.4 \pm 6) \mu \mathrm{J}$ and an average fluence of $(34.9 \pm 7) \mathrm{mJ} \mathrm{cm} \mathrm{cm}^{-2}$. The insets show selected regions of the ToF mass spectra in more detail to highlight the less dominant products. The masses of the products corresponding to simple ionic species and carbon clusters ions are labelled in black and red, respectively. 
masses of $27,28,29$ and 30 , respectively. The increased intensity of 28 amu with respect to the others in this series points to an additional contribution from $\mathrm{CO}^{+}$which, along with $\mathrm{CO}_{2}{ }^{+}$observed at $44 \mathrm{amu}$, is consistent with the formation of neutral $\mathrm{CO}$ and $\mathrm{CO}_{2}$ resulting from the irradiation of $\mathrm{CH}_{4}: \mathrm{H}_{2} \mathrm{O}$ ices as observed at lower photon energies. ${ }^{23,24}$ The peak at 30 amu could also contain a contribution from $\mathrm{H}_{2} \mathrm{CO}^{+}$ while that at 32 amu could correspond to both $\mathrm{O}_{2}^{+}$and $\mathrm{CH}_{3} \mathrm{OH}^{+}$. However, the lack of a clearly observable signal at 33 amu corresponding to $\mathrm{CH}_{3} \mathrm{OD}^{+}$would appear to rule out the latter. Finally, we note that the peak at 44 amu might also be attributed to acetaldehyde $\left(\mathrm{CH}_{3} \mathrm{CHO}^{+}\right)$.

The most striking observation is the appearance of the additional family of broader desorption peaks separated by ca. 12 amu which appear to be shifted to non-integer mass values. Given the otherwise clear alignment of peaks with the mass scale, this does not appear to be related to the calibration of the ToF. Furthermore, there does not appear to be a consistent separation between adjacent peaks on the mass scale, rather the spacing increases with mass. It was found that by shifting the flight time by $-80 \mathrm{~ns}$ all of the peaks in this family aligned to integer multiples of $12 \mathrm{amu}$, consistent with the desorption of a series of carbon clusters $\left(\mathrm{C}_{n}{ }^{+}\right)$with $n$ values of up to at least 12, noting that the mass range of the ToF mass spectrometer was around 150 amu. ToF mass spectra on a shotto-shot basis revealed that the signals corresponding to the carbon cluster ions strongly depend on fluence, dominating the spectrum for individual pulses with a higher energy, while the simple ionic species were observed more consistently for all pulse energies. However, there is no clear evolution of the shotto-shot mass spectra as a function of overall irradiation time. In order to gain more insight into this behaviour, the fluence dependence of the desorption signals was assessed.

\subsection{Fluence dependence of desorption signals}

The fluence dependence of the desorption yield of a particular desorption product provides some insight into the underlying photochemical mechanism. For example, a single photon process which results in the ejection of a product would be expected to show a linear dependence of the desorption yield on the fluence. On the other hand a mechanism requiring multiple photons, for example the recombination of fragments from separate primary fragmentation processes, or those involving multi-photon excitations, would be expected to result in non-linear dependencies. During the acquisition of the ToF mass spectra, the FEL fluence was simultaneously recorded for each FEL laser shot allowing, for each desorption product, the fluence dependence to be assessed. In general, the desorption yield can be expressed according to:

$$
Y \sim I^{K}
$$

where $Y$ is the desorption yield, $I$ denotes the laser fluence and $K$ is the order of non-linearity, with $K=1$ corresponding to a simple first order, single photon process. The order of the nonlinearity can be determined by plotting the fluence dependence in double logarithmic form, the slope of which yields the value of $K$. The fluence measurements were not performed on a fresh layer and the beam was incident on the same spot throughout. However, fluence dependence measurements were not performed in any sequential order but randomly on the basis of the simultaneously recorded fluence. Fig. 3 shows the fluence dependencies for the simple ionic species discussed in the previous section. For example, the yield of $\mathrm{H}^{+}$displays a clear linear fluence dependence, consistent with a single photon process involving $\mathrm{CH}_{4}$. Likewise, the yield associated with 2 amu shows a near linear dependence of $K=1.3$ suggesting that it is dominated by a similar single photon process involving $\mathrm{D}^{+}$ desorption from $\mathrm{D}_{2} \mathrm{O}$ with the departure from linearity perhaps suggesting an additional contribution from $\mathrm{H}_{2}{ }^{+}$. In a few cases, the fluence dependence of the desorption signal could not be clearly assigned due to a small ion signal or an overlap of a small ion signal with a large neighbouring signal.

While the simple ionic products tend to show fluence dependencies in the range $1 \leq K \leq 3$, the desorption of $\mathrm{C}_{n}{ }^{+}$ clusters exhibit highly non-linear dependencies on the FEL fluence. Fig. 4 shows the fluence dependencies for all of the carbon cluster ions detected with the exception of $\mathrm{C}_{12}{ }^{+}$which displays a very small desorption signal. Values of $K$ between 6 and 10 were obtained as shown in Fig. 4. At the highest fluences the desorption signal shows saturation for the $\mathrm{C}_{n}{ }^{+}$clusters, as seen in Fig. 4. However, for the simple ionic products the desorption signal even decreases by about an order of magnitude, as can be noticed in Fig. 3. Such a decrease in the desorption signal of the simple ions points to a change in the chemistry at the highest fluences. It may possibly be assigned to the further dissociation of the simple ions. Therefore, for the determination of $K$, the desorption signal at the highest fluences is not taken into account. Table 2 summarizes the masses of all detected ions and their possible assignments along with the value of $K$ derived from the fluence dependence measurements.

\subsection{Two-pulse correlation measurements}

In the cases where a non-linear fluence dependence was observed, two-pulse correlation measurements were performed to gain further insight into the dynamics. ${ }^{13,38}$ In these measurements, the FEL pulses were split into two nominally equal intensity components that could be temporally separated by $\Delta t=-2$ to + 6 ps. In the case of simple ions and the photochemical products, the temporal behaviour is shown in Fig. 5. Those products containing some contribution from the $\mathrm{D}_{2} \mathrm{O}$ component of the ice mixture show a minimum in the desorption signal at $\Delta t=0 \mathrm{ps}$ and increasing with increasing delay between the two partial beams. Previously, Siemer et al. ${ }^{13}$ performed two-pulse correlation measurements for the ionic desorption products resulting from the XUV irradiation of pure $\mathrm{D}_{2} \mathrm{O}$ ice. They found that the desorption signal of all the observed ions also exhibited a minimum in intensity at $\Delta t=0$ with the signal increasing with increasing delay, with a maximum at around $\Delta t=2.2 \mathrm{ps}$. In the present study, in order to quantify the timescale for the processes that lead to the desorption of these species, a rise time fit was performed. A Boltzmann sigmoidal function was used for the fitting as this correctly reproduces the form of the 


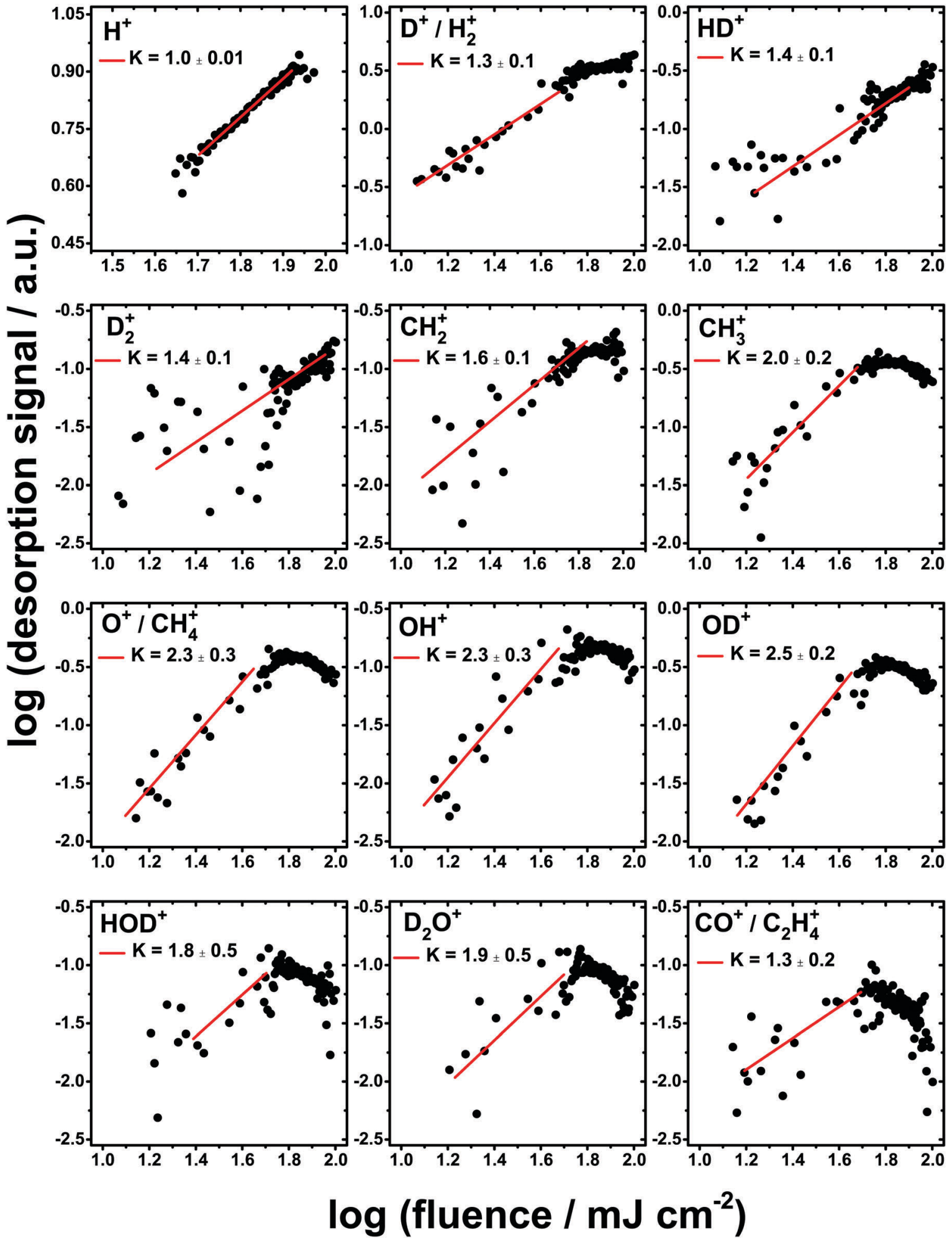

Fig. 3 Fluence dependence of the yield of various simple ionic species formed, photo-desorbed during the irradiation of a $\mathrm{CH}_{4}: \mathrm{D}_{2} \mathrm{O} 1: 3.3$ ice mixture adsorbed on the HOPG surface at $15 \mathrm{~K}$. The slopes of the straight line fits give the order of non-linearity, $K$. The desorption signal at highest fluence is not taken into account for the determination of $K$ as discussed in the text.

correlation curve, with the increase to a plateau at long values of $\Delta t$. The rise time $t_{\mathrm{r}}$, i.e. the delay for which the desorption signal reaches $50 \%$ of the plateau value, was obtained from the fits which are shown in red in Fig. 5. Values of $t_{\mathrm{r}}$ between 1.7 and 2.3 ps were obtained for the ionic species that desorb containing some contribution from the $\mathrm{D}_{2} \mathrm{O}$ parent species. 

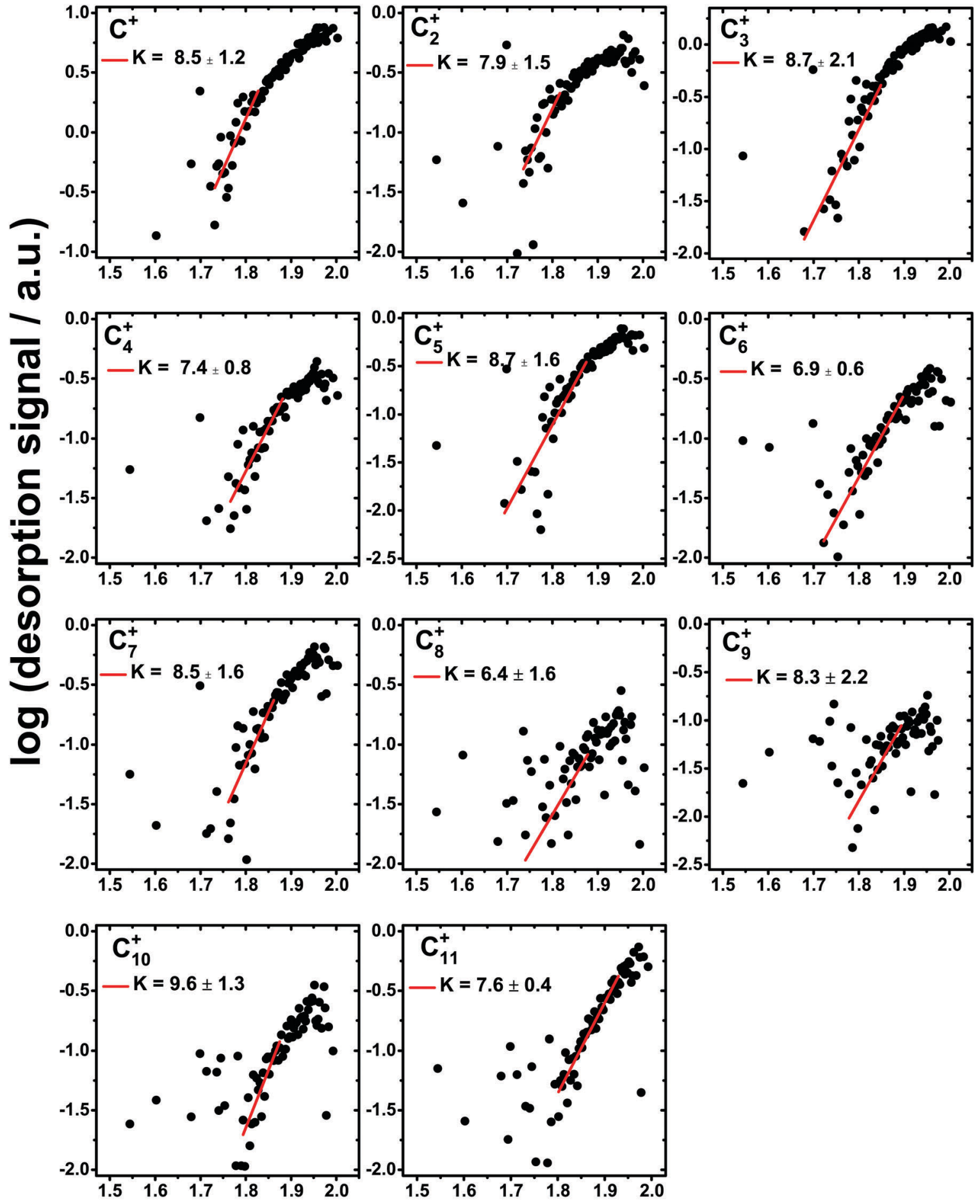

log (fluence $/ \mathrm{mJ} \mathrm{cm}^{-2}$ )

Fig. 4 Fluence dependence of the yield of various carbon cluster ions formed, photo-desorbed during the irradiation of a $\mathrm{CH}_{4}: \mathrm{D}_{2} \mathrm{O} 1: 3.3$ ice mixture adsorbed on the HOPG surface at $15 \mathrm{~K}$. The slopes of the straight line fits give the order of non-linearity, $K$. The desorption signal at highest fluence is not taken into account for the determination of $K$ as discussed in the text.

All of the $\mathrm{C}_{n}^{+}$ions exhibit a maximum at $\Delta t=0$ and a rapid reduction in intensity with increasing delay, as shown in Fig. 6. A Gaussian fit to the experimental correlation curve yields a full width at half maximum (FWHM) of $\sim 1.2 \mathrm{ps}$. The rise time value obtained above for ionic species which have contributions from the $\mathrm{D}_{2} \mathrm{O}$ molecule can be compared to the half width at 
Table 2 Possible mass assignment for photo-desorbed ions and the order of non-linearity, $K$, from fluence dependence plots

\begin{tabular}{|c|c|c|}
\hline Mass/amu & Possible ions & Non-linearity, $K$ \\
\hline 1 & $\mathrm{H}^{+}$ & $1.0 \pm 0.01$ \\
\hline 2 & $\mathrm{D}^{+} / \mathrm{H}_{2}^{+}$ & $1.3 \pm 0.1$ \\
\hline 3 & $\mathrm{HD}^{+}$ & $1.4 \pm 0.1$ \\
\hline 4 & $\mathrm{D}_{2}^{+}$ & $1.4 \pm 0.1$ \\
\hline 12 & $\mathrm{C}^{+}$ & $8.5 \pm 1.2$ \\
\hline 14 & $\mathrm{CH}_{2}^{+}$ & $1.6 \pm 0.1$ \\
\hline 15 & $\mathrm{CH}_{3}^{+}$ & $2.0 \pm 0.2$ \\
\hline 16 & $\mathrm{CH}_{4}^{+} / \mathrm{O}^{+}$ & $2.3 \pm 0.3$ \\
\hline 17 & $\mathrm{OH}^{+}$ & $2.3 \pm 0.3$ \\
\hline 18 & $\mathrm{OD}^{+}$ & $2.5 \pm 0.2$ \\
\hline 19 & $\mathrm{HOD}^{+}$ & $1.8 \pm 0.5$ \\
\hline 20 & $\mathrm{D}_{2} \mathrm{O}^{+}$ & $1.9 \pm 0.5$ \\
\hline 24 & $\mathrm{C}_{2}^{+}$ & $7.9 \pm 1.5$ \\
\hline 26 & $\mathrm{C}_{2} \mathrm{H}_{2}^{+}$ & \\
\hline 27 & $\mathrm{C}_{2} \mathrm{H}_{3}^{+}$ & \\
\hline 28 & $\mathrm{CO}^{+} / \mathrm{C}_{2} \mathrm{H}_{4}^{+}$ & $1.3 \pm 0.2$ \\
\hline 29 & $\mathrm{C}_{2} \mathrm{H}_{5}^{+}$ & \\
\hline 30 & $\mathrm{C}_{2} \mathrm{H}_{6}^{+} / \mathrm{H}_{2} \mathrm{CO}^{+}$ & \\
\hline 32 & $\mathrm{O}_{2}^{+}$ & \\
\hline 36 & $\mathrm{C}_{3}^{+}$ & $8.7 \pm 2.1$ \\
\hline 40 & $\mathrm{C}_{3} \mathrm{H}_{4}^{+} /\left(\mathrm{D}_{2} \mathrm{O}\right)_{2}^{+}$ & \\
\hline 44 & $\mathrm{CO}_{2}^{+} / \mathrm{C}_{3} \mathrm{H}_{8}{ }^{+} / \mathrm{CH}_{3} \mathrm{CHO}^{+}$ & \\
\hline 48 & $\mathrm{C}_{4}^{+}$ & $7.4 \pm 0.8$ \\
\hline 60 & $\mathrm{C}_{5}^{+}$ & $8.7 \pm 1.6$ \\
\hline 72 & $\mathrm{C}_{6}^{+}$ & $6.9 \pm 0.6$ \\
\hline 84 & $\mathrm{C}_{7}^{+}$ & $8.5 \pm 1.6$ \\
\hline 96 & $\mathrm{C}_{8}^{+}$ & $6.4 \pm 1.6$ \\
\hline 108 & $\mathrm{C}_{9}^{+}$ & $8.3 \pm 2.2$ \\
\hline 120 & $\mathrm{C}_{10}{ }^{+}$ & $9.6 \pm 1.3$ \\
\hline 132 & $\mathrm{C}_{11}^{+}$ & $7.6 \pm 0.4$ \\
\hline 144 & $\mathrm{C}_{12}{ }^{+}$ & \\
\hline
\end{tabular}

half maximum of Gaussian fits to the correlation curves obtained for the carbon cluster ions. This comparison suggests a significantly shorter timescale for processes leading to the ejection of the carbon cluster ions compared to the $\mathrm{D}_{2} \mathrm{O}$ derived products. Interestingly, the two-pulse correlation measurements for the signal at $15 \mathrm{amu}$ show a temporal behaviour strikingly similar to that observed for the carbon cluster ions. Compared to the other signals in this region of the mass spectrum, this mass can only be attributed to $\mathrm{CH}_{3}{ }^{+}$while those at higher masses can also be attributed to oxygen containing species derived from $\mathrm{D}_{2} \mathrm{O}$. A significant background is observed for $\mathrm{CH}_{3}{ }^{+}$which further suggest an additional contribution due to a single photon process in the ejection of $\mathrm{CH}_{3}{ }^{+}$. The two-pulse correlation curves shown in Fig. 5 and 6 have an asymmetric peak shape which is most likely due to a slight difference in intensity between two partial beams delivered by the SDU.

\section{Discussion}

At the employed photon energy of $40.8 \mathrm{eV}$, there is sufficient energy to drive a complex chemistry involving ionization and inner valence shell excitations, which is consistent with the observed production and desorption of ionic species. It is important to note that our measurements provide insight only into the desorption of these ionic products and that anion and neutral desorption, as well as the retention of products in the solid state, is likely to also occur. An attempt was made to probe the desorption of neutral species through a laser radiation at $\lambda=266 \mathrm{~nm}$. The detection sensitivity for neutrals by $266 \mathrm{~nm}$ non-resonant multi-photon ionization is not as high as for the direct detection of desorbing ions. However, investigation of the mass spectra showed clear signals for the desorption of neutral hydrogen and carbon atoms. Nevertheless, we would expect the relative yield of the neutrals to be greater than that of the positive ion signals.

We begin first by focussing on the observed ionic desorption products that can be attributed solely to the $\mathrm{D}_{2} \mathrm{O}$ component of the ice mixture. These ions include $\mathrm{D}^{+}, \mathrm{D}_{2}^{+}, \mathrm{O}^{+}, \mathrm{OD}^{+}, \mathrm{D}_{2} \mathrm{O}^{+}$and $\mathrm{O}_{2}{ }^{+}$. These ions were observed previously during the XUV irradiation of pure $\mathrm{D}_{2} \mathrm{O}$ ice ${ }^{13}$ and were described in terms of a reaction scheme involving first the dissociation of the $\mathrm{D}_{2} \mathrm{O}$ molecule and the ejection of $\mathrm{D}^{+}$and $\mathrm{OD}^{+}$. The close to linear fluence dependence of the $\mathrm{D}^{+}$signal at mass 2 suggests that a direct single photon process dominates the ejection of $\mathrm{D}^{+}$. Orlando et al..$^{39}$ observed strong $\mathrm{H}^{+}$electron stimulated desorption (ESD) from $\mathrm{H}_{2} \mathrm{O}$ which was attributed to the Coulomb explosion of 2-hole states, generated through the primary excitation event, with population of the dissociative $4 \mathrm{a}_{1}$ state driving the $\mathrm{H}^{+}$desorption. The observed threshold was $22 \mathrm{eV}$, significantly lower than the photon energy employed in the present measurements. Such a mechanism for proton ejection was also associated with photon stimulated dissociation of the $\mathrm{H}_{2} \mathrm{O}$ molecule. ${ }^{40}$ It is reasonable that the same channel operates in the present case, giving rise to the observed linear fluence dependence. ESD measurements ${ }^{39}$ also indicated a single electron process with a threshold again at $22 \mathrm{eV}$ for the desorption of $\mathrm{H}_{2}{ }^{+}$which was attributed to a dissociative ionization involving direct molecular elimination. The observed yield of $\mathrm{H}_{2}{ }^{+}$was $c a$. 50 times less than that of $\mathrm{H}^{+}$, similar to our observed $\mathrm{D}_{2}^{+}: \mathrm{D}^{+}$yield ratio of around $1: 50$, suggesting that a similar mechanism is likely involved.

The desorption of $\mathrm{O}^{+}$and $\mathrm{OD}^{+}$both show a non linear fluence dependence with $K=2.3$ and 2.5, respectively, indicative of a process involving 2 photons, for example through the ionization and dissociation of the OD generated as a result of the primary $\mathrm{D}^{+}$ejection. Similarly, a three-step process suggested previously ${ }^{13}$ involving $\mathrm{D}_{2} \mathrm{O}_{2}$, formed through OD recombination, acting as a reservoir species is also consistent with the observed fluence dependence of both $\mathrm{O}^{+}$and $\mathrm{OD}^{+}$. Subsequent fragmentation of $\mathrm{D}_{2} \mathrm{O}_{2}$ provides energetically favorable pathways to many of the fragments observed. ${ }^{41}$ We note that in the present case, no direct observation of $\mathrm{D}_{2} \mathrm{O}_{2}{ }^{+}$desorption was possible at $36 \mathrm{amu}$ as this overlaps with the strong signal attributed to $\mathrm{C}_{3}{ }^{+}$. For pure $\mathrm{D}_{2} \mathrm{O}$ ice a non-linear dependence of $K=3$ was observed for $\mathrm{O}_{2}^{+}$ desorption while in the present case no clear dependence on the intensity of this peak with fluence was observed. The non-linear fluence dependence $(K \approx 2)$ observed for $\mathrm{D}_{2} \mathrm{O}^{+}$suggests that a direct ejection is not the dominant mechanism, and that $\mathrm{D}^{+}$is the dominant result of the primary excitation. Fragmentation of $\mathrm{D}_{2} \mathrm{O}_{2}{ }^{41}$ provides a potential route toward $\mathrm{D}_{2} \mathrm{O}^{+}$, while $\left(\mathrm{OD}+\mathrm{D}^{+}\right)$ and $\left(\mathrm{OD}^{+}+\mathrm{D}\right)$ provide alternative routes toward $\mathrm{D}_{2} \mathrm{O}^{+} \cdot{ }^{42}$ Finally, we note the presence of signals at 3 and $17 \mathrm{amu}$ which can be attributed to $\mathrm{HD}^{+}$and $\mathrm{OH}^{+}$, respectively. The strong $\mathrm{H}^{+}$signal dominates the ionic desorption spectrum, with a linear fluence 

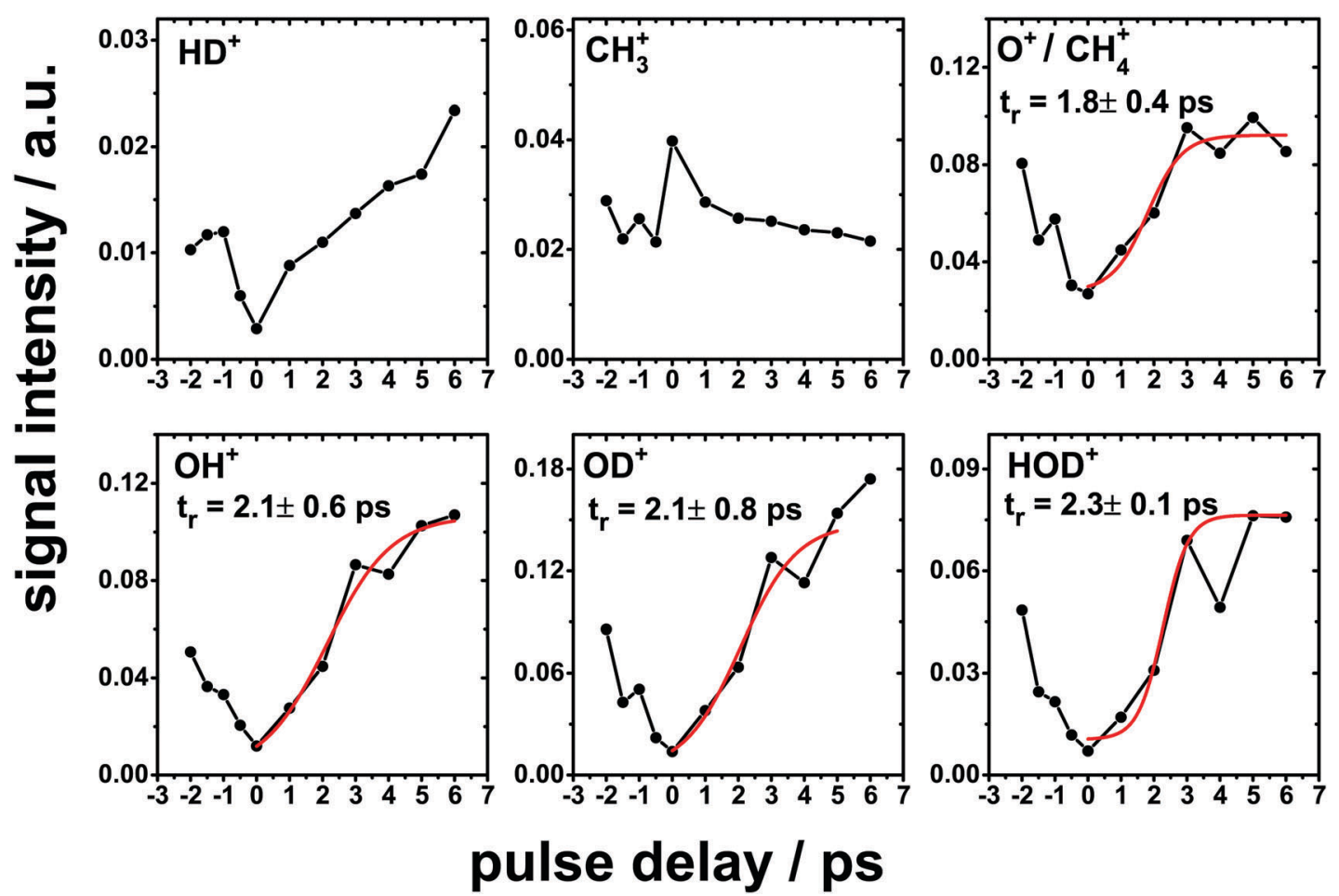

Fig. 5 Two-pulse correlation measurements of the XUV desorption of various simple ionic species from a $\mathrm{CH}_{4}: \mathrm{D}_{2} \mathrm{O} 1: 3.3$ ice mixture adsorbed and measured on the HOPG surface at $15 \mathrm{~K}$ (black data). The photon energy of the FEL pulse was $h \nu=40.8 \mathrm{eV}$. The Boltzmann sigmoidal function (red curve) was used to fit the experimental curve. The corresponding rise time $t_{r}$ is the desorption signal which reaches $50 \%$ of the plateau value obtained from the fit and is given for each plot.

dependence that suggests a simple single photon process that releases a proton which can then produce $\mathrm{HD}^{+}$and $\mathrm{OH}^{+}$through recombination reactions with other ion fragments.

The most striking feature in the ion desorption spectrum shown in Fig. 2 is the series of peaks separated by 12 amu that correspond to $\mathrm{C}_{n}{ }^{+}$ions. We observe ions with $n$ values of up to 12 , as limited by the range of our ToF mass spectrometer. The formation of neutral $\mathrm{C}_{n}$ clusters as a result of the VUV $(\lambda=120 \mathrm{~nm})$ photolysis of solid methane has been observed recently by Lin et al. ${ }^{43}$ They exposed $\mathrm{CH}_{4}$ dispersed in solid neon at a molar ratio of $1: 1000$ to synchrotron radiation and observed, through infrared spectroscopy, the signatures of carbon clusters and hydrocarbon molecules. In the present case, as discussed above, the starting point for the carbon chemistry is likely the single photon ejection of a proton from the $\mathrm{CH}_{4}$ molecule. Dissociative auto ionization of $\mathrm{CH}_{4}$ has been observed in the gas phase through low energy electron excitation with a threshold of $22 \mathrm{eV}^{44}$ and provides a viable route:

$$
\begin{gathered}
\mathrm{CH}_{4}+h \nu \rightarrow \mathrm{CH}_{4}{ }^{*} \\
\mathrm{CH}_{4}{ }^{*} \rightarrow \mathrm{CH}_{3}\left(\tilde{\mathrm{X}}^{2} \mathrm{~A}_{2}^{\prime \prime}\right)+\mathrm{H}^{+}+\mathrm{e}^{-}
\end{gathered}
$$

Subsequent ionization and fragmentation of the $\mathrm{CH}_{3}$ radical could then account for the observed signals at 14 and $15 \mathrm{amu}$ corresponding to $\mathrm{CH}_{2}{ }^{+}$and $\mathrm{CH}_{3}{ }^{+}$, consistent with their nonlinear fluence dependencies of $K=1.6$ and 2.1, respectively.
Either $\mathrm{CH}_{4}{ }^{+}$or $\mathrm{O}^{+}$could account for the observed signal at $16 \mathrm{amu}$, although as with the case of $\mathrm{D}_{2} \mathrm{O}^{+}$which shows a rather small signal, $\mathrm{O}^{+}$would appear to be the major contribution. This is supported by the temporal dependence obtained for this mass through the two-pulse correlation measurements which behaves in a similar way to the other $\mathrm{D}_{2} \mathrm{O}$ fragments.

In addition to ionic $\mathrm{D}_{2} \mathrm{O}$ fragments and the carbon cluster ions, we also observe a series of peaks centered around $28 \mathrm{amu}$. This mass region is consistent with the formation of $\mathrm{C} 2$ hydrocarbons of the general form $\mathrm{C}_{2} \mathrm{H}_{y}{ }^{+}$with $(2 \leq y \leq 6)$, corresponding to the range $26-30 \mathrm{amu}$. The peak at $28 \mathrm{amu}$ is clearly the strongest, and would correspond to $\mathrm{C}_{2} \mathrm{H}_{4}{ }^{+}$. It shows a near linear fluence dependence which is somewhat difficult to reconcile with a reaction mechanism that involves the initial fragmentation of two parent $\mathrm{CH}_{4}$ molecules. Unfortunately, the overlap between the peaks in this region precludes an assessment of the fluence dependence for the other masses.

We note that the formation of $\mathrm{CO}^{+}$can also contribute to the signal at $28 \mathrm{amu}$, and similarly $\mathrm{CO}_{2}{ }^{+}$to that at $44 \mathrm{amu}$, both of which are frequently observed during the energetic processing of mixed hydrocarbon and water ices. ${ }^{16,22-24} \mathrm{C}_{3}$ hydrocarbons of the general formula $\mathrm{C}_{3} \mathrm{H}_{z}{ }^{+}$with $(z=4,6,8)$ might be expected to give another series of peaks above $36 \mathrm{amu}$ although we only see clear peaks at 40 and $44 \mathrm{amu}$. Bossa et al. ${ }^{19}$ observed the formation of linear $\mathrm{C}_{2}$ and $\mathrm{C}_{3}$ hydrocarbons as a result of VUV irradiation of pure $\mathrm{CH}_{4}$ ice indicating that recombination of methane fragments within an ice film can provide a route 

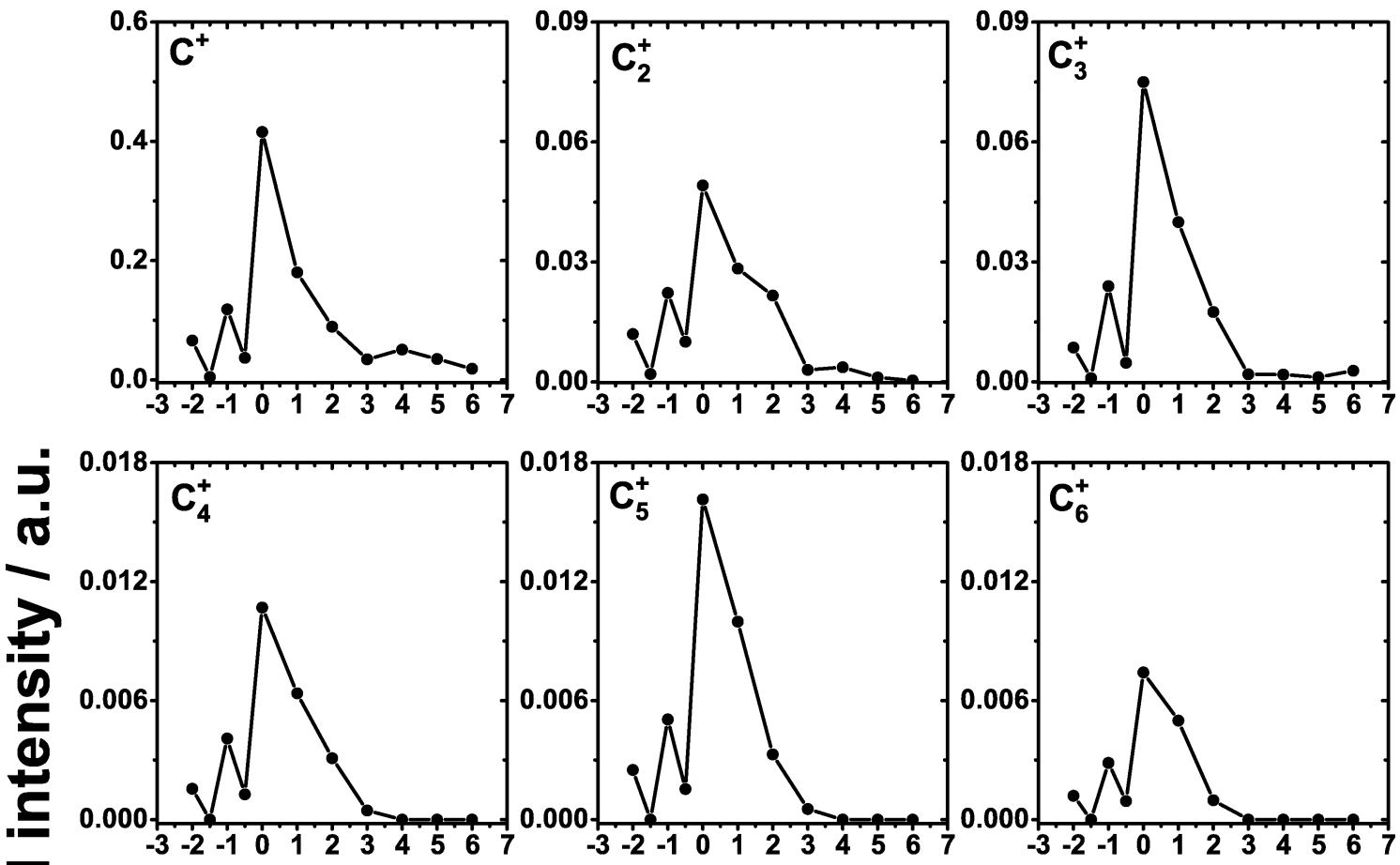

它
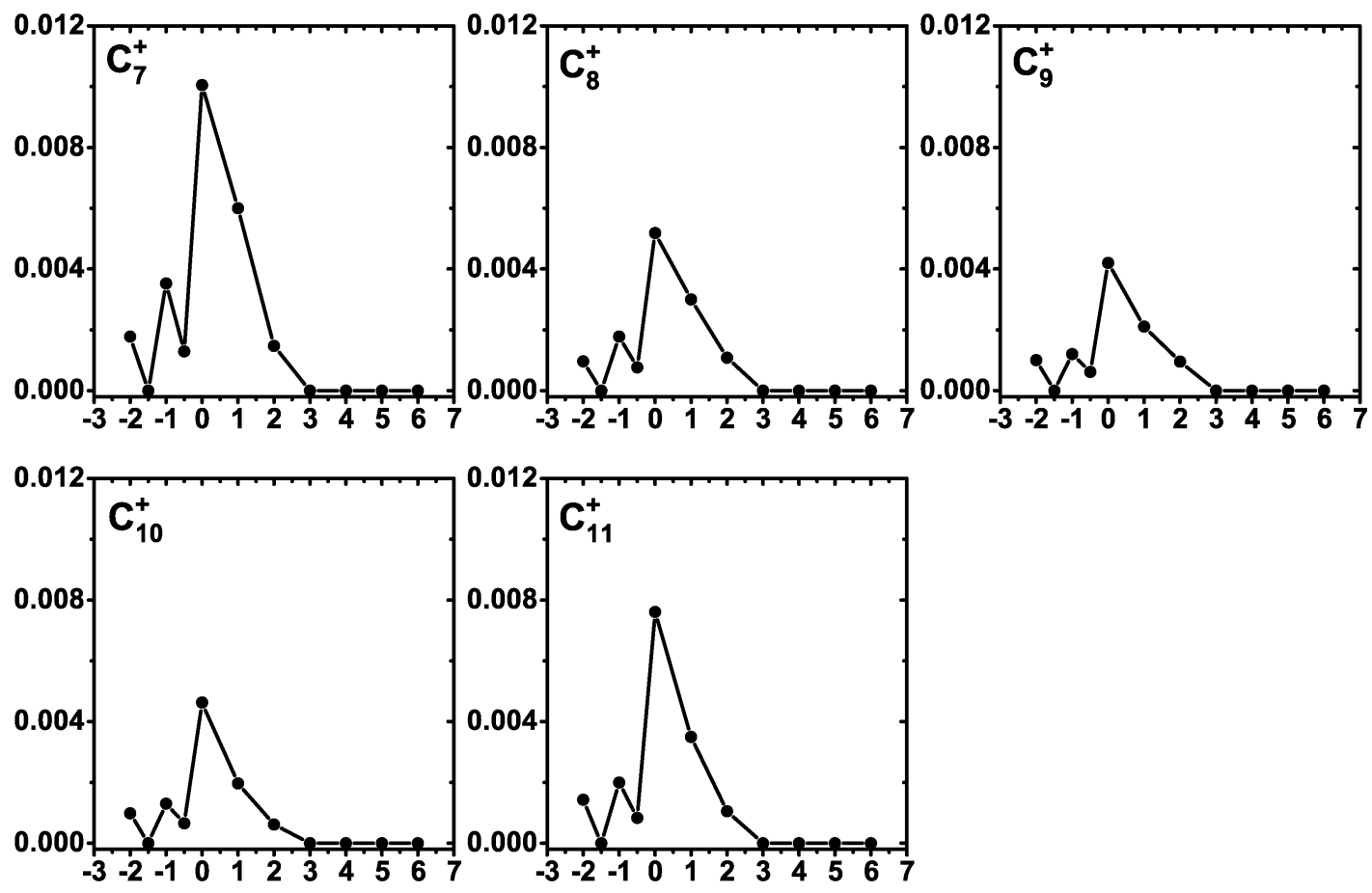

pulse delay / ps

Fig. 6 Two-pulse correlation measurements of the XUV desorption of carbon cluster ions from a $\mathrm{CH}_{4}: \mathrm{D}_{2} \mathrm{O} 1: 3.3$ ice mixture adsorbed on the HOPG surface kept at $15 \mathrm{~K}$. The photon energy of the FEL pulse was $h \nu=40.8 \mathrm{eV}$.

toward larger hydrocarbons. Given the parent molecules present in the ice, $\mathrm{CH}_{3} \mathrm{OD}$ (or $\mathrm{CH}_{3} \mathrm{OH}$ ) formation might also be expected although, as discussed above, the clear non-detection of the former at $33 \mathrm{amu}$ would appear to rule this out, considering that $\mathrm{CH}_{3} \mathrm{OD}$ would be expected to form more readily from the primary fragments. Cruz-Diaz et al. ${ }^{45}$ also observed little $\mathrm{CH}_{3} \mathrm{OH}$ desorption during VUV irradiation of $\mathrm{CH}_{3} \mathrm{OH}$ ice, attributing this to fragmentation being the dominant channel, which in our case would return any methanol that is formed to the primary fragments. We note that we cannot rule out the presence of 
$\mathrm{CH}_{3} \mathrm{OD}$, or indeed other solid state species such as hydrocarbons in the exposed ice column, as our experimental approach is sensitive only to ions that desorb directly from the ice.

Previous studies of the energetic processing of pure $\mathrm{CH}_{4}$ ice have focussed on those species that are retained in the solid state. For example, Bossa et al. ${ }^{19}$ used VUV photons, dominated by Lyman- $\alpha$, to initiate photochemical reactions in pure $\mathrm{CH}_{4}$ ice. Species formed in the ice were subsequently thermally desorbed from the ice with a laser heating pulse with $\mathrm{CH}_{x}$ $(x=1-3), \mathrm{C}_{2} \mathrm{H}_{y}(y=2,4,6)$ and $\mathrm{C}_{3} \mathrm{H}_{z}(z=4,6,8)$ being identified. Similarly, ion irradiation of pure $\mathrm{CH}_{4}$ ice with $60 \mathrm{keV} \mathrm{Ar}{ }^{2+}, 16$ $220 \mathrm{MeV}^{16} \mathrm{O}^{7+18}$ and $15.7 \mathrm{MeV}^{16} \mathrm{O}^{5+46}$ have been shown to result in the production of hydrocarbons including $\mathrm{C}_{2} \mathrm{H}_{2}$ (acetylene), $\mathrm{C}_{2} \mathrm{H}_{4}$ (ethylene), $\mathrm{C}_{2} \mathrm{H}_{6}$ (ethane), and $\mathrm{C}_{3} \mathrm{H}_{8}$ (propane) in the solid state as identified through infrared spectroscopy. The electron bombardment reaction of pure $\mathrm{CH}_{4}$ ice by $5 \mathrm{keV}$ energetic electrons ${ }^{17}$ also resulted in the formation of $\mathrm{CH}_{x}(x=1-4)$ and $\mathrm{C}_{2} \mathrm{H}_{y}(y=2-6)$ in the ice which was interpreted in terms of the sequential loss of mobile $\mathrm{H}$ atoms from $\mathrm{CH}_{4}$ and subsequent reactions between the radical species thus formed. It is therefore clear that similar reaction pathways are operative at the higher photon energy used in the present study and we cannot rule out the formation of these neutral species which are then retained in the solid state. Rather, in addition, ionization becomes important at higher photon energies, permitting the direct ejection of ionic species from the ice.

Similarly, for $\mathrm{CH}_{4}: \mathrm{H}_{2} \mathrm{O}$ mixed ice, previous ion ${ }^{16,22}$ and VUV photon irradiation ${ }^{23,24,47}$ measurements have been performed revealing the formation of a variety of species such as $\mathrm{CO}, \mathrm{CO}_{2}$, $\mathrm{H}_{2} \mathrm{CO}, \mathrm{CH}_{3} \mathrm{OH}, \mathrm{CH}_{3} \mathrm{CHO}$ and $\mathrm{CH}_{3} \mathrm{CH}_{2} \mathrm{OH}$. As with the pure $\mathrm{CH}_{4}$ derived species, we observe the ejection of some species that can be attributed to reactions between fragments originating from the two ice components. However, as discussed for the case of $\mathrm{CH}_{3} \mathrm{OD}$, if any of these species are formed in the ice, subsequent destruction is dominant over ionization and ejection. We previously assigned the peak observed at $40 \mathrm{amu}$ to $\left(\mathrm{D}_{2} \mathrm{O}\right)_{2}{ }^{+13}$ but the absence of the deuterated cluster $\left(\mathrm{D}_{2} \mathrm{O}\right)_{2} \mathrm{D}^{+}$ at 42 amu suggests otherwise. Propyne, $\mathrm{C}_{3} \mathrm{H}_{4}$, could also be a potential candidate for the signal observed at $40 \mathrm{amu}$.

The temporal behaviour of the desorption yields shows two distinct behaviours that allow us to separate the ionic desorption into two families. The species that correspond to ions that can be attributed directly to processes involving only the $\mathrm{CH}_{4}$ component of the ice, i.e. the $\mathrm{C}_{n}{ }^{+}$clusters and $\mathrm{CH}_{3}{ }^{+}$, show a desorption behaviour in which the desorption yield is peaked when the two partial beams are temporally overlapped. For longer delays between the two partial beams, the desorption yield falls rapidly such that the correlation curves show a FWHM of $c a .1 .2 \mathrm{ps}$ for $\mathrm{C}_{n}{ }^{+}$. The form of the correlation curve for the $\mathrm{CH}_{4}$ derived species is consistent with the highly non-linear fluence dependencies associated with these ions. This suggests that their formation requires a significant input of energy within a short time in order to generate sufficient reactive fragments to form larger carbon containing species that can lead to the observed carbon cluster desorption. On the other hand, species that have a contribution from the $\mathrm{D}_{2} \mathrm{O}$ component of the ice display a contrasting behaviour, where a minimum in the desorption yield is observed when the partial beams are temporally overlapped, with the yield increasing for longer delays. To quantify this effect, a rise time of ca. 2 ps was evaluated from the temporal behaviour of the desorption signal of the species forming from either $\mathrm{D}_{2} \mathrm{O}$ alone or fragments of both of the parents. This can be compared to the half width at half maximum of the temporal response for the carbon cluster ions $(0.6 \mathrm{ps})$. The timescale for the formation and desorption of the $\mathrm{C}_{n}{ }^{+}$clusters is therefore significantly shorter than that for the other species, which show a desorption signal that does not decrease even at the longest temporal delays possible with the SDU (6 ps). Previously, collisions between ion fragments were suggested as a possible reason for the longer desorption timescale for ionic species desorbing from pure $\mathrm{D}_{2} \mathrm{O}$ ice upon XUV irradiation, ${ }^{13}$ being consistent with the present observations. This effect can also be present here due to the involvement of an additional ice constituent, $\mathrm{CH}_{4}$, and the additional reaction pathways that lead to the carbon cluster ions. However, without further insight into the evolution of the condensed phase during irradiation this remains somewhat speculative.

In addition to the clear difference in the temporal behaviour of the two families of ions observed, there is also an apparent delay of $c a .80 \mathrm{~ns}$ for the $\mathrm{C}_{n}{ }^{+}$ions with respect to the other species. This might suggest the ejection of parent species that fragment at some later time yielding the observed cations. Lin et $a l^{43}$ observed the formation of neutral carbon clusters $\mathrm{C}_{n}(n=3-20)$, as well as simple hydrocarbons, resulting from the VUV photolysis of solid $\mathrm{CH}_{4}$ dispersed in neon at $3 \mathrm{~K}$. Interestingly, the size distribution of the observed clusters shifted to higher $n$ with an increasing degree of dilution and no $\mathrm{C}_{n}$ was observed from pure $\mathrm{CH}_{4}$. Raghavachari and Binkley ${ }^{48}$ performed $a b$ initio calculations and studied the stabilities of small ionic carbon clusters $\mathrm{C}_{n}(n=2-10)$. They showed that the odd-numbered $\mathrm{C}_{n}{ }^{+}$clusters (up to $n=7$ ) are more stable than the even-numbered clusters. This study is consistent with the results obtained here which show that signal intensities of odd-numbered $\mathrm{C}_{n}{ }^{+}$clusters are larger than those of the even numbered $\mathrm{C}_{n}{ }^{+}$.

Interestingly, no ion signal for methanol, a molecule of interstellar relevance in terms of the formation of more complex organic species, was observed as already discussed above. Similarly, rather than resulting in the significant desorption of hydrocarbon species, dehydrogenation appears to be important at these energies leading primarily to the ejection of bare carbon cluster ions. Monitoring of the solid state composition of the ice during irradiation would be necessary to confirm the presence of hydrocarbon species. Neutral carbon clusters are molecules of interstellar importance and have been suggested as a possible carrier of the diffuse interstellar bands (DIBs) and unidentified infrared (UIR) emission bands. ${ }^{49-51}$ The present investigation suggests that photon induced processing of hydrocarbon species at high photon energies might provide a route toward the production of such species. However, the strong non-linear fluence dependence observed would tend to limit their formation under interstellar conditions. 


\section{Conclusion}

Femtosecond pulsed XUV radiation from the FLASH FEL with a photon energy $h \nu=40.8 \mathrm{eV}(\lambda=30.4 \mathrm{~nm})$ was used to irradiate a $\mathrm{CH}_{4}: \mathrm{D}_{2} \mathrm{O} 1: 3.3$ ice mixture adsorbed on an HOPG surface at $15 \mathrm{~K}$. The XUV radiation induces chemical reactions in the ices and the desorption of cationic species that directly desorb from the ice film, where they can be detected through ToF mass spectrometry. The desorption of simple ionic species that result from the fragmentation of the parent molecules, $\mathrm{D}_{2} \mathrm{O}$ and $\mathrm{CH}_{4}$, in the ice was identified and include $\mathrm{D}^{+}, \mathrm{O}^{+}, \mathrm{OD}^{+}, \mathrm{H}^{+}, \mathrm{CH}_{3}{ }^{+}$and $\mathrm{CH}_{2}{ }^{+}$. Reaction products formed through the recombination of these primary fragments were also observed through the desorption of $\mathrm{HD}^{+}, \mathrm{O}_{2}{ }^{+}, \mathrm{HDO}^{+}$and $\mathrm{CO}^{+}$. In addition, simple hydrocarbons of the general formula $\mathrm{CH}_{x}{ }^{+}(x=1-4), \mathrm{C}_{2} \mathrm{H}_{y}{ }^{+}(1 \leq$ $y \leq 6)$ and $\mathrm{C}_{3} \mathrm{H}_{z}{ }^{+}(z=4,8)$ were also identified. The ejection of these cationic species demonstrates that at higher photon energies, ionization plays an important role in the chemistry taking place in the ice, with several of the observed cationic desorption products being comparable to those obtained through electron irradiation of ices in the 20-100 eV regime. As well as these relatively simple ionic species, we also observed the ejection of $\mathrm{C}_{n}{ }^{+}$clusters (with up to $n=12$ ).

Fluence dependence measurements were performed for the detected ionic desorption products to provide further insight into the mechanisms of the underlying photochemical processes. The simple species tended to show a low order of non-linearity up to $K=3$ consistent with reactions between fragments formed from the parent species present in the ice. On the other hand, the desorption signals for the carbon clusters show highly non-linear fluence dependencies of up to $K>9$, suggesting that multiple reaction steps involving primary fragments are required to generate these larger species. A surprising observation is that although the $\mathrm{C}$ concentration in the ice mixture was smaller than the $\mathrm{O}$ abundance, an efficient carbon chemistry was observed. Rather than generating hydrocarbon species, including those containing functional groups such as OD from the $\mathrm{D}_{2} \mathrm{O}$ component of the ice, the higher energy photons appear to drive a chemistry dominated by the formation of bare carbon clusters. This is consistent with the strong $\mathrm{H}^{+}$desorption signal which indicates that dehydrogenation is an important step in initiating the formation of the carbon species.

The two-pulse correlation measurements, performed using a split-and-delay unit, revealed that the simple ions can be attributed to the fragmentation of the $\mathrm{D}_{2} \mathrm{O}$ component of the ice. They showed an unexpected behaviour in which the desorption yield shows a minimum at $\Delta t=0 \mathrm{ps}$, corresponding to the temporal overlap of two pulses. The $\mathrm{D}_{2} \mathrm{O}$ derived ionic species show a longer timescale of $c a .2$ ps estimated from the rise time of a Boltzmann sigmoidal fit to the desorption signal which increases as a function of delay time between the two partial beams. The behaviour is consistent with that observed previously for pure $\mathrm{D}_{2} \mathrm{O}$ ice ${ }^{13}$ and can similarly be attributed to collisions between the ionic fragments. On the other hand, the carbon cluster ions show a maximum at close to $\Delta t=0 \mathrm{ps}$. This suggests that the formation of the carbon cluster ions requires a significant input of energy on a short timescale, consistent with the need to activate multiple $\mathrm{CH}_{4}$ molecules in order to drive the complex multistep chemistry. This timescale for the $\mathrm{C}_{n}{ }^{+}$ionic species was estimated to be 1.2 ps as determined from the FWHM of a Gaussian fit to the correlation curve.

\section{Conflicts of interest}

There are no conflicts to declare.

\section{Acknowledgements}

The authors acknowledge financial support from the European Commission's 7th Framework Programm through the "LASSIE" ITN under Grant Agreement Number 238258 and the NRW International Graduate School of Chemistry, Münster. We would also like to acknowledge the European Union and Horizon 2020 funding awarded under the Marie Skłodowska-Curie action to the EUROPAH consortium, grant number 722346 .

\section{References}

1 K. I. Öberg, Chem. Rev., 2016, 116, 9631-9663.

2 A. C. A. Boogert, P. A. Gerakines and D. C. B. Whittet, Annu. Rev. Astron. Astrophys., 2015, 53, 541-581.

3 L. J. Allamandola, M. P. Bernstein, S. A. Sandford and R. L. Walker, Space Sci. Rev., 1999, 90, 219-232.

4 T. P. Snow and A. N. Witt, Astrophys. J., Lett., 1996, 468, L65. 5 S. Ioppolo, H. M. Cuppen and H. Linnartz, Rendiconti Lincei, 2011, 22, 211-224.

6 H. M. Butner, S. B. Charnley, C. Ceccarelli, S. D. Rodgers, J. R. Pardo, B. Parise, J. Cernicharo and G. R. Davis, Astrophys. J., Lett., 2007, 659, L137.

7 B. T. Draine, Astrophys. J., Suppl. Ser., 1978, 36, 595-619.

8 S. S. Prasad and S. P. Tarafdar, Astrophys. J., 1983, 267, 603-609.

9 P. G. Judge and A. Pietarila, Astrophys. J., 2004, 606, 1258.

10 H. Peter, B. V. Gudiksen and ̊. Nordlund, Astrophys. J., 2006, 638, 1086.

11 M. Nuevo, Y.-J. Chen, W.-J. Hu, J.-M. Qiu, S.-R. Wu, H.-S. Fung, C.-C. Chu, T.-S. Yih, W.-H. Ip and C.-Y. R. Wu, Astrobiology, 2014, 14, 119-131.

12 R. R. Meier, Space Sci. Rev., 1991, 58, 1-185.

13 B. Siemer, S. Roling, R. Frigge, T. Hoger, R. Mitzner and H. Zacharias, Faraday Discuss., 2014, 168, 553-569.

14 A. C. A. Boogert, F. P. Helmich, E. F. van Dishoeck, W. A. Schutte, A. G. G. M. Tielens and D. C. B. Whittet, Astron. Astrophys., 1998, 336, 352-358.

15 R. I. Kaiser and K. Roessler, Astrophys. J., 1998, 503, 959.

16 G. A. Baratta, M. Domingo, G. Ferini, G. Leto, M. E. Palumbo, M. A. Satorre and G. Strazzulla, Nucl. Instrum. Methods Phys. Res., Sect. B, 2003, 209, 283-287.

17 C. J. Bennett, C. S. Jamieson, Y. Osamura and R. I. Kaiser, Astrophys. J., 2006, 653, 792. 
18 A. L. F. de Barros, V. S. D. E. Bordalo, E. S. Duarte, E. F. da Silveira, A. Domaracka, H. Rothard and P. Boduch, Astron. Astrophys., 2011, 531, A160.

19 J.-B. Bossa, D. M. Paardekooper, K. Isokoski and H. Linnartz, Phys. Chem. Chem. Phys., 2015, 17, 17346-17354.

20 J.-I. Lo, M.-Y. Lin, Y.-C. Peng, S.-L. Chou, H.-C. Lu, B.-M. Cheng and J. F. Ogilvie, Mon. Not. R. Astron. Soc., 2015, 451, 159-166.

21 R. Dupuy, M. Bertin, G. Féraud, X. Michaut, P. Jeseck, M. Doronin, L. Philippe, C. Romanzin and J.-H. Fillion, Astron. Astrophys., 2017, 603, A61.

22 M. H. Moore and R. L. Hudson, Icarus, 1998, 135, 518-527.

23 R. Hodyss, P. V. Johnson, J. V. Stern, J. D. Goguen and I. Kanik, Icarus, 2009, 200, 338-342.

24 K. I. Öberg, E. F. van Dishoeck, H. Linnartz and S. Andersson, Astrophys. J., 2010, 718, 832.

25 J. E. Bartmess and R. M. Georgiadis, Vacuum, 1983, 33, 149-153.

26 D. Chakarov, L. Österlund and B. Kasemo, Vacuum, 1995, 46, 1109-1112.

27 J. M. Gay, A. Dutheil, J. Krim and J. Suzanne, Surf. Sci., 1986, 177, 25-35.

28 K. P. Stevenson, G. A. Kimmel, Z. Dohnalek, R. S. Smith and B. D. Kay, Science, 1999, 283, 1505-1507.

29 G. A. Kimmel, K. P. Stevenson, Z. Dohnalek, R. S. Smith and B. D. Kay, J. Chem. Phys., 2001, 114, 5284-5294.

30 U. Raut, M. Famá, B. D. Teolis and R. A. Baragiola, J. Chem. Phys., 2007, 127, 204713.

31 M. Á. Satorre, M. Domingo, C. Millán, R. Luna, R. Vilaplana and C. Santonja, Planet. Space Sci., 2008, 56, 1748-1752.

32 K. Tiedtke, A. Azima, N. von Bargen, L. Bittner, S. Bonfigt, S. Düsterer, B. Faatz, U. Frühling, M. Gensch and C. Gerth, et al., New J. Phys., 2009, 11, 023029.

33 R. Mitzner, B. Siemer, M. Neeb, T. Noll, F. Siewert, S. Roling, M. Rutkowski, A. Sorokin, M. Richter and P. Juranic, et al., Opt. Express, 2008, 16, 19909-19919.
34 S. Roling, B. Siemer, M. Wöstmann, H. Zacharias, R. Mitzner, A. Singer, K. Tiedtke and I. Vartanyants, Phys. Rev. Spec. Top.-Accel. Beams, 2011, 14, 080701.

35 M. Wöstmann, R. Mitzner, T. Noll, S. Roling, B. Siemer, F. Siewert, S. Eppenhoff, F. Wahlert and H. Zacharias, J. Phys. B: At., Mol. Opt. Phys., 2013, 46, 164005.

36 B. L. Henke, E. M. Gullikson and J. C. Davis, At. Data Nucl. Data Tables, 1993, 54, 181-342.

37 T. Mukai and S. Mukai, Adv. Space Res., 1984, 4, 207-210.

38 F. Budde, T. F. Heinz, M. M. T. Loy, J. A. Misewich, F. De Rougemont and H. Zacharias, Phys. Rev. Lett., 1991, 66, 3024.

39 T. M. Orlando, A. B. Aleksandrov and J. Herring, J. Phys. Chem. B, 2003, 107, 9370-9376.

40 D. E. Ramaker, Chem. Phys., 1983, 80, 183-202.

41 S. N. Foner and R. L. Hudson, J. Chem. Phys., 1962, 36, 2676-2680.

42 K. T. Gillen, B. H. Mahan and J. S. Winn, J. Chem. Phys., 1973, 58, 5373-5384.

43 M.-Y. Lin, J.-I. Lo, H.-C. Lu, S.-L. Chou, Y.-C. Peng, B.-M. Cheng and J. F. Ogilvie, J. Phys. Chem. A, 2014, 118, 3438-3449.

44 R. Locht, J. Olivier and J. Momigny, Chem. Phys., 1979, 43, 425-432.

45 G. A. Cruz-Diaz, R. Martín-Doménech, G. M. Muñoz Caro and Y.-J. Chen, Astron. Astrophys., 2016, 592, A68.

46 F. A. Vasconcelos, S. Pilling, W. R. M. Rocha, H. Rothard, P. Boduch and J. J. Ding, Phys. Chem. Chem. Phys., 2017, 19, 12845-12856.

47 R. Martín-Doménech, G. M. M. Caro and G. A. Cruz-Díaz, Astron. Astrophys., 2016, 589, A107.

48 K. Raghavachari and J. S. Binkley, J. Chem. Phys., 1987, 87, 2191-2197.

49 J. Fulara and J. Krełowski, New Astron. Rev., 2000, 44, 581-597.

50 J. P. Maier, N. M. Lakin, G. A. H. Walker and D. A. Bohlender, Astrophys. J., 2001, 553, 267.

51 L. Horný, N. D. Petraco and H. F. Schaefer, J. Am. Chem. Soc., 2002, 124, 14716-14720. 